\title{
Insertional activation of myb by F-MuLV in SCID mice induces myeloid leukemia
}

\author{
MEHRAN HAERI ${ }^{1,2}$, YOUJUN LI $^{2,3}$, YANMEI LI $^{2}$, QI LI $^{3}$, DAVID E. SPANER $^{1,2}$ and YAACOV BEN-DAVID ${ }^{1,2}$ \\ ${ }^{1}$ Department of Medical Biophysics, University of Toronto; ${ }^{2}$ Division of Molecular and Cellular Biology, Sunnybrook \\ Health Sciences Centre, Toronto, Canada; ${ }^{3}$ Norman Bethune College of Medicine, Jilin University, Changchun, P.R. China
}

Received March 2, 2013; Accepted April 18, 2013

DOI: $10.3892 /$ ijo.2013.1943

\begin{abstract}
Identification of retrovirus integration sites is a powerful method to identify cancer-related genes. This approach led to the discovery of the Friend murine leukemia virus (F-MuLV) integration site-1 (fli-l). Viral insertion at the $f i-1$ locus induces erythroleukemia in susceptible strains of mice. Our recent data demonstrated that, F-MuLV-infected SCID mice, in contrast to wt CB17 controls, developed a non-erythroleukemic leukemia without viral integration at the fli- 1 locus. Using ligation-mediated polymerase chain reaction (LM-PCR) approach we identified a total of 15 viral integration sites in F-MuLV-infected SCID mice. One of the identified insertion sites was located about $62 \mathrm{~kb}$ upstream of the myeloblastosis ( $m y b$ ) gene. While integration within or surrounding the $m y b$ gene has been reported before for murine leukemia viruses, the location of the viral integration site identified in F-MuLV-infected SCID mice is novel and has never been reported. Using PCR analysis we showed that viral integration at the $m y b$ locus occurs with a frequency of $35 \%$ and therefore is considered as a common integration site. Integration of F-MuLV in this locus resulted in upregulation of the MYB protein. Flow cytometry analysis and methylcellulose culture of leukemic cells isolated from tumors with viral integration close to the $m y b$ indicated tumors of myeloid origin. Our findings indicate that, in contrast to wt CB17 mice, F-MuLV-infected SCID mice display viral integration within myeloid specific gene loci that result in the development of myelogenous leukemia.
\end{abstract}

\section{Introduction}

Retroviruses induce cancers by integrating into the genome and altering the expression of interrupted genes and/or genes flanking the insertion sites that have oncogenic or tumor

Correspondence to: Professor Yaacov Ben-David, Present address: The Key Laboratory of Chemistry for Natural Products of Guizhou Province and Chinese Academy of Sciences, Guiyang 550002, P.R. China

E-mail: ybd1955@gmail.com

Key words: Friend erythroleukemia, proviral integration, myeloblastosis oncogene, myeloid leukemia suppressor ability. In the past, cloning of the viral integration site has resulted in the identification of many cancer genes associated with proliferation, differentiation and apoptosis (1).

Friend murine leukemia virus (F-MuLV)-induced erythroleukemia has been used as an excellent model to identify and characterize genetic events involved in the induction and progression of erythroleukemia. The initial induction of erythroleukemias induced by F-MuLV is due to the insertional activation of the Ets transcription factor Fli-1. Activation of Fli-1 in erythroblasts blocks differentiation and promotes proliferation in response to erythropoietin (Epo) stimulation (2). Progression to the advanced stage of the disease was shown to be associated with the insertional inactivation of either tumor suppressor genes p53 (3) or P45 NFE2 (4). In a recent study, our group has also identified the activation of the microRNA cluster miR-17-92 in a subset of erythroleukemias induced by F-MuLV in p53-deficient mice (5).

In addition to these genetic events, our previous study revealed the importance of the tumor microenvironment in the progression of F-MuLV-induced erythroleukemias (6). Since F-MuLV induces erythroleukemia only in newborn mice, the presence of a weaker immune system may explain leukemia development in these mice as opposed to adult mice. To further explore the role of immune cells in the progression of F-MuLV-induced erythroleukemias, the immunodeficient SCID mice were inoculated with this virus and disease progression was monitored. In this study we have shown that SCID mice infected with F-MuLV develop leukemia with a lower frequency when compared to the control CB17 mice. Interestingly, F-MuLV-infected SCID mice developed myelogenous leukemia, but not erythroleukemia. We have shown that SCID mice, when compared to wt CB17 controls exhibit an altered proviral integration pattern resulting in the activation of genes associated with myelogenous leukemia.

\section{Materials and methods}

F-MuLV production. To harvest F-MuLV, mouse NIH-3T3 cells that contain F-MuLV genome (known as clone 57 cells) (7) were cultured in Dulbecco's Modified Eagle's Medium (Invitrogen, Burlington, ON, Canada) supplemented with fetal bovine serum (FBS) (Invitrogen) to the final concentration of $10 \%$, penicillin/streptomycin (Invitrogen) to the final concentration of $100 \mathrm{IU} / \mathrm{ml}$ for penicillin and $100 \mathrm{~g} / \mathrm{ml}$ for 
streptomycin, and 2-mercaptoethanol (Sigma, Oakville, ON, Canada) to the final concentrations of $0.2 \mathrm{mM}$. After cells reached confluence, the culture supernatant was transferred to a $50 \mathrm{ml}$ conical tube (Sarstedt, Montreal, QC, Canada) on ice and centrifuged at $3,900 \times \mathrm{g}$ at $4^{\circ} \mathrm{C}$ for $30 \mathrm{~min}$. The supernatant was then transferred into a glass beaker on ice, sonicated (Branson sonifier, Model 250) for 10 pulses, with output control adjusted at 2.5 and duty cycle on constant position. The sonicated supernatant was then filter sterilized through a $0.22 \mu \mathrm{m}$ filter (Millipore, Billerica, MT, USA), mixed by pipetting up and down, and aliquoted in $1 \mathrm{ml}$ volume in polypropylene tubes (Becton-Dickinson, Franklin Lakes, NJ, USA). After standing for $15 \mathrm{~min}$ on ice the aliquots were stored at $-80^{\circ} \mathrm{C}$.

Tumor induction. Newborn mice, 1-2 days-old, were inoculated, intraperitoneally with $100 \mu \mathrm{l}$ of the clone 57 cells supernatant containing F-MuLV (equal to 500 focal forming units) via a 1-cc U-100 insulin syringe (Becton-Dickinson). Animal studies and procedures were according to the Sunnybrook Health Sciences Centre animal care committee.

Cell line generation. Spleens from F-MuLV-infected SCID mice were excised and placed in sterile $1 \mathrm{X}$ phosphate-buffered saline (PBS), followed by mechanical homogenization using a mortar and pestle and 2 washes in PBS. Cells were cultured in $\alpha$-Minimal Essential Medium (Invitrogen), supplemented with $20 \%$ FBS (Invitrogen), $10 \mathrm{ng} / \mathrm{ml}$ interleukin (IL)-3 (Invitrogen), $10 \mathrm{ng} / \mathrm{ml}$ stem cell factor (R\&D Systems, Minneapolis, MN, USA) and $1 \mathrm{U} / \mathrm{ml}$ erythropoietin (Boehringer Mannheim, Montreal, QC, Canada). Cells were then allowed to expand for 3-4 days until adherent and suspension cells were easily discernible. At this time, $50 \%$ of the media was exchanged with fresh media every 3 days. After 3-5 such cycles cell lines were established, as indicated by their proliferation rate in the culture.

DNA isolation. DNA extraction from F-MuLV-inoculated or non-inoculated SCID and CB17 mice was performed as follows: splenic tissue (100-200 mg) was placed into $10 \mathrm{ml}$ of DNA extraction buffer [Tris, $\mathrm{pH} 7.8(0.05 \mathrm{M})$, EDTA $(0.02 \mathrm{M}), \mathrm{NaCl}(0.15 \mathrm{M})]$ and cells were dissociated by the plunger of a $2 \mathrm{ml}$ syringe followed by pipetting up and down using a 21 gauge needle. The solution was then filtered through a $40 \mu \mathrm{m}$ cell strainer (Becton-Dickinson). Sodium dodecyl sulfate (Sigma) and proteinase $\mathrm{K}$ (Invitrogen) were added to final concentrations of $1 \%$ and $50 \mathrm{~g} / \mathrm{ml}$, respectively and the solution was incubated at $56^{\circ} \mathrm{C}$ for $4 \mathrm{~h}$. Phenol (BioShop, Burlington, ON, Canada), pre-warmed to $65^{\circ} \mathrm{C}$, was added and mixed by inverting several times. The tube was centrifuged, the upper aqueous phase was transferred to a fresh tube and an equal volume of phenol:chloroform:isoamyl alcohol (Fisher Scientific, Nepean, ON, Canada) (25:24:1) was added. The solution was mixed by inversion and then centrifuged. The upper phase was isolated a second time and an equal volume of chloroform:isoamyl alcohol (24:1) was added. The solution was mixed by inversion and then centrifuged. The upper phase was transferred to a fresh tube on ice and ethanol (pre-cooled to $-20^{\circ} \mathrm{C}$ ) was slowly added up to a total volume of $50 \mathrm{ml}$. DNA precipitate was transferred to $10 \mathrm{mM}$ Tris, $\mathrm{pH} 8.0$ for future use. All centrifugations were performed at $2,800 \mathrm{x} \mathrm{g}$ for $15 \mathrm{~min}$.

Histology. Spleen tissues were fixed in $10 \%$ neutral buffered formalin (Sigma) for $24 \mathrm{~h}$. The tissues were then cut into sections with thickness of $5 \mu \mathrm{m}$ and stained with hematoxylin and eosin. Dr Geoffrey A. Wood at the University of Guelph performed histopathology examination of the tissues.

Flow cytometry. Cell surface marker profile of spleens of the F-MuLV-infected mice was determined by flow cytometry analysis. Spleen cells were washed in PBS and resuspended in FACS staining buffer (Hanks' balanced salt solution containing $0.1 \%$ sodium azide and $1 \%$ bovine serum albumin). Ten million cells of each sample were incubated $\left(4^{\circ} \mathrm{C} ; 10 \mathrm{~min}\right)$ with anti-CD16/CD32 antibody to block non-specific binding. Cells were then incubated with CD19, CD3, B220, Gr1, CD11b, TER119, CD71, cKit, Sca1 or CD34 primary antibodies $\left(4^{\circ} \mathrm{C}\right.$; $30 \mathrm{~min}$ ) and washed twice in FACS staining buffer. Equal to ten thousand events were collected using a FACSCalibur flow cytometer (Becton-Dickinson) and analyzed with FlowJo software (Tree Star, San Carlos, CA, USA). All antibodies were purchased from eBiosciences (San Diego, CA, USA).

Southern blot analysis. DNA samples $(10 \mu \mathrm{g})$ from spleens of F-MuLV-infected mice were digested with BamHI enzyme (New England Biolabs, Ipswich, MA, USA). The digested samples were run on a $0.7 \%$ agarose gel at 33 volts for $30 \mathrm{~h}$. The DNA samples were transferred to a zeta-probe membrane (Bio-Rad, Hercules, CA, USA) using 0.4 M NaOH solution and then transferred to a UV cross-linker (UV Stratalinker, Stratagene, Santa Clara, CA, USA) to cross-link DNA to the membrane. The membrane was then hybridized with P32-labeled B2 probe (8) and detected on a radiographic film.

Ligation-mediated polymerase chain reaction (LM-PCR). GenomeWalker Universal Kit (Clontech Laboratories, Mountain View, CA, USA) was used to amplify F-MuLV-host DNA junction fragments. Genomic DNA $(25 \mu \mathrm{g})$ was digested by DraI, EcoRV, PvuII, or StuI restriction enzymes. The digested DNA was extracted by phenol/chloroform and resuspended in TE (10/0.1, pH 7.5). The following reagents were added to the digested, purified DNA: GenomeWalker adaptor $(6 \mu \mathrm{M})$, ligation buffer (2X) and T4 DNA ligase (3 units). The reaction mixture was incubated at $16^{\circ} \mathrm{C}$ overnight. Gene specific primer 1 (GSP1) and adaptor primer 1 (AP1) were used for primary PCR to amplify F-MuLV-host DNA junction fragment(s). The primer sequences were as follows: GSP1 (AAGGACCTGAAATGACCCTGTGCCTTA), AP1 (GTAATACGACTCACTATAGGGC). For secondary (nested) PCR, 1/50 dilution of the primary PCR product was used as template and the sequences of the primers, GSP2 and AP2, were as follows: GSP2 (TAAAAGAGCTCACAACCCCT CACTCGG), AP2 (ACTATAGGGCACGCGTGGT). Secondary PCR products were run on an agarose gel and DNA bands extracted using Quick Gel DNA Extraction kit (Invitrogen) and cloned (PCR cloning kit; Qiagen, Mississauga, ON, Canada). The purified cloned DNA samples were sequenced, at the Center for Applied Genomics (Toronto, ON, Canada), 
using GSP2 or AP2 primers. The homology of each sequence with mouse genome databank was determined in the Ensembl database, using the BLAT (Basic Local Alignment Search Tool-like Alignment Tool) software.

Western blot analysis. Expression of Myb in spleens of the SCID mice with viral integration at the $m y b$ locus was determined by western blot analysis. Spleen $\left(\sim 0.5 \mathrm{~cm}^{2}\right)$ was lysed in $1 \mathrm{ml}$ of Radio Immuno Precipitation Assay buffer [Tris, pH 8.0 (50 mM), $\mathrm{NaCl}(50 \mathrm{mM}), \mathrm{NP}-40(1 \%)$, sodium deoxycholate $(0.5 \%)$, SDS (0.1\%)] supplemented with aprotinin $(2 \mu \mathrm{g} / \mathrm{ml})$, leupeptin $(5 \mu \mathrm{g} / \mathrm{ml})$, PMSF $(1 \mathrm{mM})$, EDTA $(5 \mathrm{mM})$, EGTA $(1 \mathrm{mM}), \mathrm{NaF}(5 \mathrm{mM})$ and $\mathrm{Na}_{3} \mathrm{VO}_{4}(1 \mathrm{mM})$. Protein sample $(20 \mu \mathrm{g})$ was electrophoresed on SDS gel. Proteins were then transferred onto an Immobilon-P membrane (Millipore, Bedford, MA, USA), blocked in 5\% milk and incubated with anti-Myb antibody (Millipore) and then HRP-conjugated anti-mouse IgG (Promega, Madison, WI, USA). Enhanced chemiluminescence kit (GE Healthcare) was used to detect proteins.

Colony formation assay. The hematopoietic phenotypes of the spleen cells of F-MuLV-infected SCID mice were analyzed using methylcellulose-based colony assays. Colony assays were performed using methylcellulose MethoCult ${ }^{\circledR}-03434$; Stem Cell Technologies, Vancouver, BC, Canada) presupplemented with $100 \mathrm{ng} / \mathrm{ml}$ murine IL-3, $200 \mathrm{ng} / \mathrm{ml}$ murine $\mathrm{KL}, 2 \mathrm{U} / \mathrm{ml}$ human EPO and $0.2 \mathrm{mmol} / 1$ hemin3'. Splenocytes were isolated, and pooled within each test group. Cells $\left(1 \times 10^{5}\right)$ were plated in triplicate wells at $1 \mathrm{ml} /$ well in $35 \mathrm{~mm}$ dishes (Costar, Cambridge, MA, USA). Plates were incubated at $37^{\circ} \mathrm{C}$ in a humidified atmosphere containing $6.5 \% \mathrm{CO}_{2}$ in air. After 7 days, cells $\left(2 \times 10^{4}\right.$ per slide) from plucked colonies were cytospun onto glass slides (1,000 rpm; $15 \mathrm{~min})$, fixed in methanol (room temperature; $5 \mathrm{~min}$ ) and air-dried. Fixed cells were stained with May-Grunwald/Giemsa according to the manufacturer's protocol (Sigma).

Statistical analysis. Statistical analyses were performed using the two-tailed Student's t-test or ANOVA with significance considered at $\mathrm{p}<0.05$ using Origin 3.5 software (Microcal Software, Northampton, MA, USA). Values are reported as mean \pm standard error $(\mathrm{SE})$.

\section{Results}

F-MuLV-inoculated immunodeficient mice display enhanced survival. To test whether the F-MuLV-induced leukemogenesis is altered in immunodeficient mice, newborn SCID $(n=10)$ and SCID/beige $(n=8)$ mice were injected, intraperitoneally (i.p.), with F-MuLV and monitored for signs of disease progression such as paleness, hunched posture, enlarged abdomen and difficulty in breathing. F-MuLV-injected CB17 $(n=6)$ and BALB/C $(n=6)$ mice, which are susceptible to F-MuLV-induced erythroleukemia, were used as immunocompetent wt controls. At 90 days post-injection (dpi) the percentage survival of SCID, SCID/beige, CB17 and BALB/c mice were 90, 87, 0 and $0 \%$, respectively (Fig. 1), indicating enhanced survival in F-MuLV-inoculated immunodeficient SCID and SCID/beige mice. However, after 5 months of postinfection, $50 \%$ of SCID and SCID/beige mice developed leukemia.

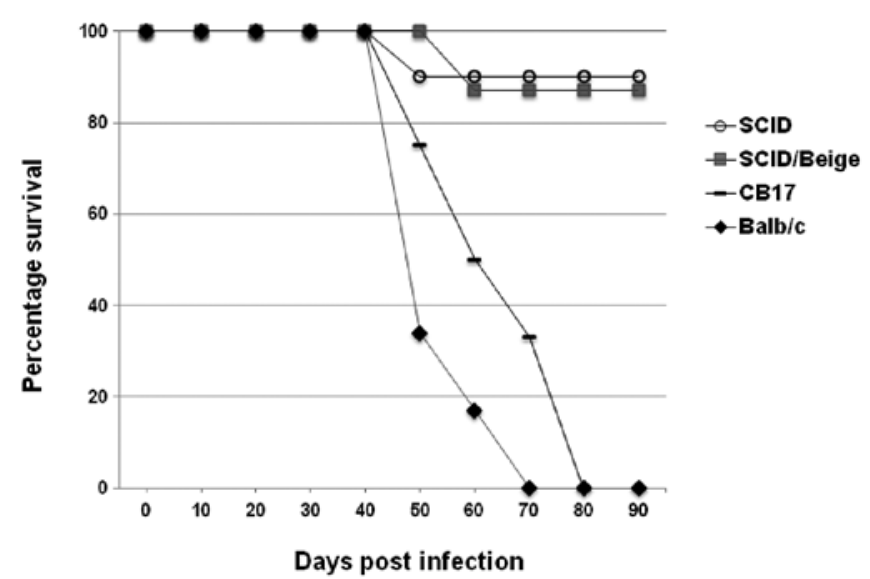

Figure 1. Survival of F-MuLV-infected mice. Newborn SCID $(n=10)$, SCID/beige $(n=8), \operatorname{CB} 17(n=6)$ and BALB/c $(n=6)$ mice were inoculated with a lethal dose of F-MuLV and monitored for disease progression. At 90 dpi the survival percentage for these mice were $90,87,0$ and $0 \%$, respectively.

Detection of F-MuLV envelope protein on the spleen cells of SCID mice indicated viral integration. The F-MuLV envelope glycoprotein 70 (gp70) is expressed on the surface of virus-infected cells and therefore can be used as a marker of viral infection. A focal immunoassay was employed for detection of gp70 expression on splenocytes isolated from F-MuLV-infected SCID mice. Cells were incubated with anti-FMuLV gp70 and horseradish peroxidase (HRP)-conjugated anti-mouse $\mathrm{IgG}$. Viral foci representing gp70 expression appeared as brown spots. Fig. 2 displays representative photographs, confirming the presence of brown foci on splenocytes from F-MuLV-infected SCID mice and the absence in uninfected mice. While these data shows that both SCID and CB17 infected mice were infected by F-MuLV, the intensity of infection is much higher in CB17 than SCID infected mice as shown in Fig. 2 and other examined leukemias (data not shown).

F-MuLV-infected SCID mice develop leukemia. To determine if in F-MuLV-infected SCID mice leukemic cells develop and accumulate in the spleen, histology sections of a normal and an enlarged spleen were stained with hematoxylin and eosin (H\&E). The same was done for virus-infected, immunocompetent CB17 mice, which served as controls. The results showed presence of leukemic cells in spleens of both F-MuLV-infected SCID and CB17 mice (Fig. 2B).

F-MuLV-infected SCID mice do not display fli-1 rearrangement. Integration of the provirus at the $f l i-1$ locus occurs in the majority of F-MuLV-induced erythroleukemias and is the pivotal genetic event in this disease (9). In order to determine if leukemic F-MuLV-infected SCID mice exhibit proviral insertion within the $f i-1$ locus, splenic DNA isolated from SCID and $\mathrm{CB} 17$ control mice was digested with BamH1 and hybridized to a $f i-1$ specific probe. DNA isolated from the F-MuLV-induced erythroleukemia cell line, CB3, which harbours viral integration within the $f l i-1$ locus was used as a positive control. Southern blot analysis revealed that while $f i-1$ rearrangement can be detected in all F-MuLV-infected CB17 mice and the erythroleukemia cell line CB3, it is absent in F-MuLV-infected 
A

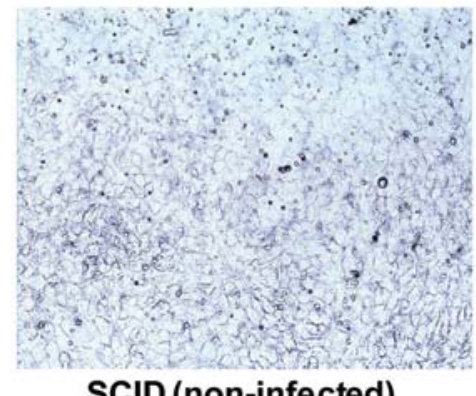

B

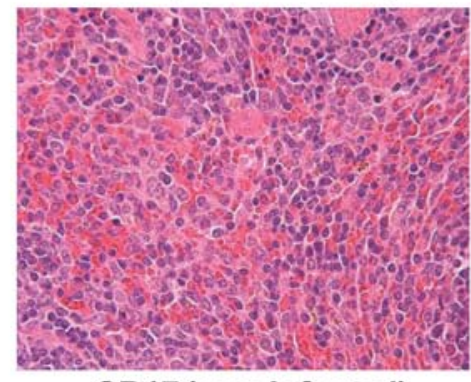

CB17 (non-infected)

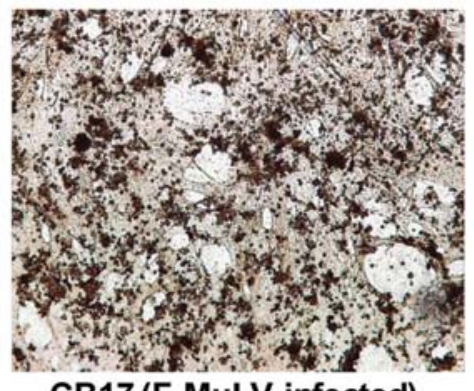

CB17 (F-MuLV-infected)

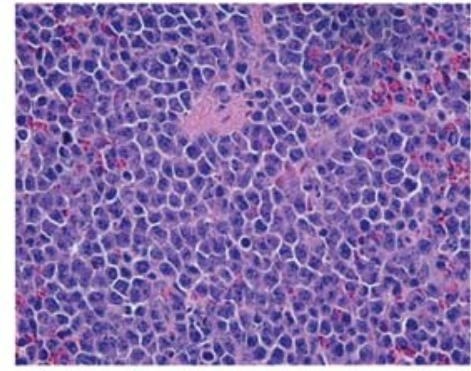

CB17 (F-MuLV-infected)
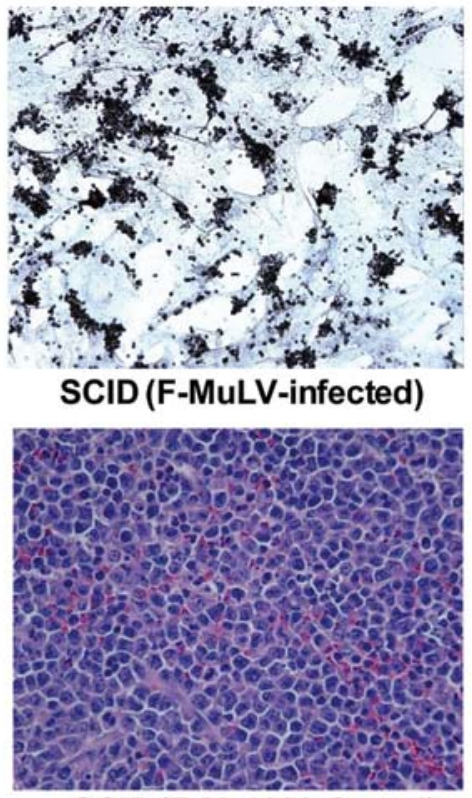

SCID (F-MuLV-infected)

Figure 2. Presence of leukemic cells in F-MuLV-infected SCID splenocytes. (A) Expression of gp70 was determined on the splenocytes of F-MuLV-injected CB17, SCID and normal (non-infected) SCID mice. The presence of gp70, identified by brown-coloured foci, was identified using an anti-gp70 antibody. Magnification, x10. (B) Presence of leukemic cells was determined in the spleens of F-MuLV-injected control CB17, SCID and non-infected CB17 mice. Splenic tissues were fixed in formalin, cut into $5 \mu \mathrm{m}$ sections, and stained with hematoxylin and eosin (magnification, $\mathrm{x} 40$ ).

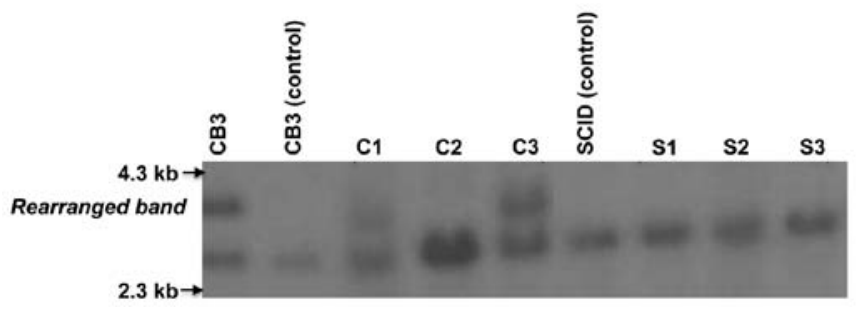

Figure 3. Detection of viral insertion within the $f i$ - 1 locus in F-MuLV-infected mice. To determine if F-MuLV-infected SCID mice exhibited viral insertion at the $f i-1$ locus, splenic DNA from SCID and control CB17 mice were digested with $B a m \mathrm{H} 1$ and labelled with radioactive-conjugated probe. DNA from non-infected SCID and CB17 mice served as negative controls, and DNA from an F-MuLV-induced erythroleukemic cell line, CB3, served as a positive control. The $f i-1$ rearrangement was not detected in F-MuLV-infected SCID mice.

SCID leukemias (Fig. 3). Our group has previously identified additional F-MuLV integration sites, within the fli-2 (p45/NFE2) (4) and $f i-3$ (miR-17-92) loci (5). Therefore, we similarly performed additional southern blot experiments, and confirmed the absence of F-MuLV integration within these sites as well (data not shown). Together these data confirm that in spite of the development of leukemia, F-MuLV-infected SCID mice do not display viral insertion within any previously identified F-MuLV common integration sites.

Ligation-mediated PCR revealed novel F-MuLV integration sites in SCID mice. The induction of leukemia and the absence of any previously known F-MuLV insertion sites led us to hypothesize that a novel integration site was responsible for F-MuLV-induced leukemia in SCID mice. Ligation-mediated
PCR approach was employed to identify viral integration sites in F-MuLV-inoculated SCID mice. DNA samples of SCID leukemic cells were digested and adaptor sequences of approximately 50 base pairs were ligated at either end of the digested fragments. Primary and nested PCR were performed using primers specific for F-MuLV and the adaptors to amplify virus-host DNA junction fragments. These amplified fragments were sequenced and homology to sequences within the mouse genome was determined in the Ensembl database. Using this approach a total of 15 insertion sites were identified in several independently-derived SCID leukemias with 7 of them located within protein coding genes (Table I).

F-MuLV integration within the myb locus occurred with a frequency of $35 \%$. In one F-MuLV-infected SCID mouse viral integration was located at approximately $62 \mathrm{~kb}$ upstream of the $m y b$ gene (Table I, Fig. 4A). This integration site was different from other proviral integration sites within the $m y b$ gene (Fig. 4A). To determine the frequency of virus integration at this site, PCR was performed to amplify virus-host DNA junction fragments in F-MuLV-infected SCID mice $(n=20)$. These PCR amplified DNA were isolated and subjected to sequencing to demonstrate their sequence identity. Amplification in 7 out of 20 DNA samples (Fig. 4B) indicated a frequency of $35 \%$, which suggested that F-MuLV integration at the $m y b$ locus is a common event in virus-inoculated leukemic SCID mice.

Myb is overexpressed in F-MuLV-inoculated SCID mice with viral integration at the myb locus. Integration of F-MuLV within the $f i-1$ locus results in overexpression of the Fli-1 protein and initiation of disease development. In order to determine if F-MuLV integration within the $m y b$ locus 
Table I. F-MuLV integration sites in SCID mice.

\begin{tabular}{|c|c|c|c|c|}
\hline Mouse no. & $\begin{array}{l}\text { Insertion location } \\
\text { (chromosome; } \\
\text { position) }\end{array}$ & $\begin{array}{l}\text { Upstream gene } \\
\quad(\sim \text { distance; } \\
\text { F-MuLV orientation } \\
\text { relative to the gene })\end{array}$ & $\begin{array}{l}\text { Downstream gene } \\
\quad \text { ( distance; } \\
\text { F-MuLV orientation } \\
\text { relative to the gene) }\end{array}$ & $\begin{array}{l}\text { Interrupted gene } \\
\text { (F-MuLV orientation } \\
\text { relative to the gene) }\end{array}$ \\
\hline 1 & $10 ; 79,834,287$ & plk5 (6 kb); [+] & $\operatorname{mex3d}(9 \mathrm{~kb}) ;[-]$ & NA \\
\hline 2 & $\begin{array}{r}2 ; 33,610,261 \\
10 ; 20,942,825\end{array}$ & $\begin{array}{r}\operatorname{lmx} 1 b(114 \mathrm{~kb}) ;[+] \\
c-m y b(62 \mathrm{~kb}) ;[-]\end{array}$ & $\begin{array}{r}p b x 3(417 \mathrm{~kb}) ;[+] \\
\text { hbs1l }(73 \mathrm{~kb}) ;[+]\end{array}$ & $\begin{array}{c}\text { fam125b }[+] \\
\text { NA }\end{array}$ \\
\hline 3 & $\begin{array}{l}14 ; 76,912,731 \\
13 ; 56,257,720\end{array}$ & $\begin{array}{l}t s c 22 d l(5 \mathrm{~kb}) ;[+] \\
h 2 a f y(20 \mathrm{~kb}) ;[+]\end{array}$ & $\begin{array}{l}\operatorname{serp} 2(20 \mathrm{~kb}) ;[-] \\
\operatorname{tifab}(17 \mathrm{~kb}) ;[+]\end{array}$ & $\begin{array}{l}\text { NA } \\
\text { NA }\end{array}$ \\
\hline 4 & $\begin{array}{r}4 ; 153,956,624 \\
17 ; 87,371,746 \\
4 ; 132,570,096 \\
7 ; 16,990,433 \\
13 ; 93,103,208\end{array}$ & $\begin{array}{r}\text { arhgefl6 }(281 \mathrm{~kb}) ;[-] \\
\text { atp6vle } 2(25 \mathrm{~kb}) ;[+] \\
\text { fgr }(12 \mathrm{~kb}) ;[+] \\
\text { sael }(17 \mathrm{~kb}) ;[-] \\
\text { rasgrf2 }(202 \mathrm{~kb}) ;[+]\end{array}$ & $\begin{array}{r}\operatorname{actrt} 2(84 \mathrm{~kb}) ;[-] \\
\operatorname{pigf}(25 \mathrm{~kb}) ;[+] \\
\text { wasf2 }(116 \mathrm{~kb}) ;[+] \\
\text { tmem160 }(48 \mathrm{~kb}) ;[+] \\
\operatorname{dhfr}(22 \mathrm{~kb}) ;[-]\end{array}$ & $\begin{array}{l}\operatorname{prdm16}[-] \\
\operatorname{rhoq}[-] \\
\operatorname{ahdc1}[+] \\
\operatorname{zc} 3 h 4[+] \\
\operatorname{msh} 3[+]\end{array}$ \\
\hline 5 & $15 ; 39,790,230$ & $\operatorname{lrp} 12(15 \mathrm{~kb}) ;[-]$ & zfpm2 (696 kb); [+] & NA \\
\hline 6 & $\begin{array}{l}13 ; 37,750,778 \\
18 ; 24,145,616\end{array}$ & $\begin{array}{r}\operatorname{ly} 86(240 \mathrm{~kb}) ;[+] \\
\text { zscan30 }(6 \mathrm{~kb}) ;[-]\end{array}$ & $\begin{array}{l}\text { rrebl }(119 \mathrm{~kb}) ;[+] \\
\quad \text { zfp35 }(3 \mathrm{~kb}) ;[-]\end{array}$ & $\begin{array}{l}\text { NA } \\
\text { NA }\end{array}$ \\
\hline 7 & $\begin{array}{l}17 ; 51,537,815 \\
16 ; 36,935,792\end{array}$ & $\begin{array}{r}\text { tbcld5 }(219 \mathrm{~kb}) ;[+] \\
\quad \operatorname{golgbl}(3 \mathrm{~kb}) ;[+]\end{array}$ & $\begin{array}{l}\text { satbl }(338 \mathrm{~kb}) ;[+] \\
\text { fbxo40 }(28 \mathrm{~kb}) ;[-]\end{array}$ & $\begin{array}{c}\text { NA } \\
h c l s 1[+]\end{array}$ \\
\hline
\end{tabular}

DNA samples from the spleens of F-MuLV-infected mice were digested and adaptor sequences of $\sim 50$ base pairs were ligated at either end of the digested fragments. Virus-host DNA junction fragments were amplified by PCR and sequenced. These isolated sequences were analyzed for homology within the mouse genome using the Ensembl database. A total of 15 insertion sites were identified, 7 of which were determined to interrupt the indicated genes. The terms 'upstream' and 'downstream' refer to the positions relative to chromosome direction, not F-MuLV DNA. All coordinates are numbered according to build NCBI/37/mm9 assembly.

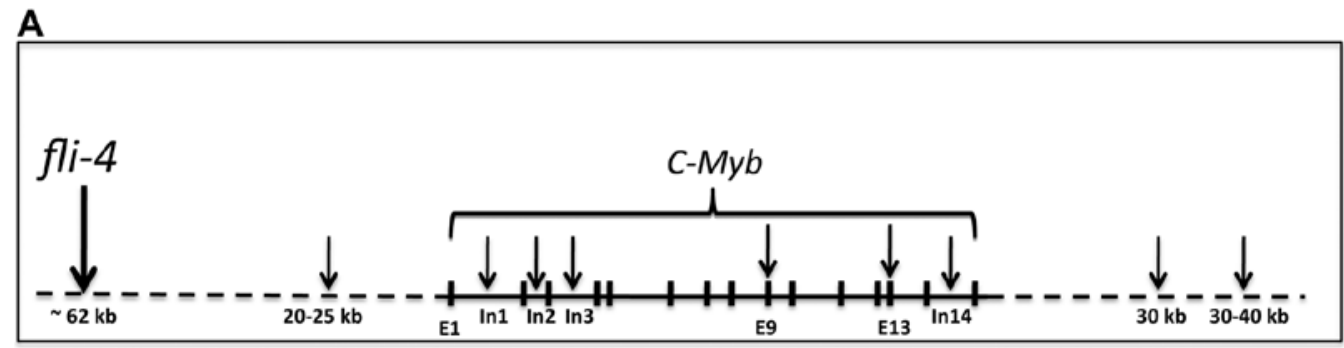

B

F-MuLV-induced tumors

negative controls

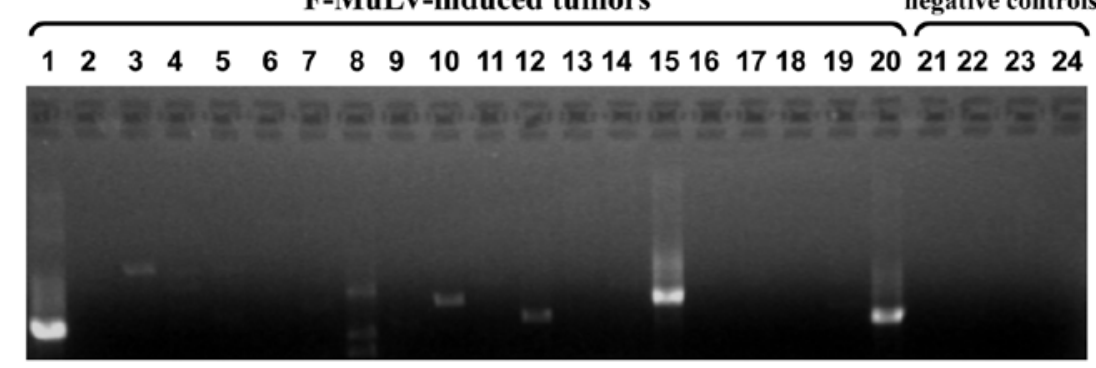

Figure 4. Integration of F-MuLV upstream of the $m y b$ gene. (A) DNA sample of an F-MuLV-infected SCID mouse was digested and adaptor sequences ( 50 bp in length) were ligated at either ends of the digested fragments. Virus-host DNA junction fragments were PCR-amplified and sequenced. The sequence was compared with those in the mouse genome and the viral integration site was determined to be approximately $62 \mathrm{~kb}$ upstream the ATG start site of the $m y b$ gene. This novel integration site was designated as $f l i-4$. (B) Based on the identified integration of F-MuLV about $62 \mathrm{~kb}$ upstream of $m y b$ in one virus-infected SCID mouse, primers were designed to perform PCR to identify the frequency of viral integration at or around the same location in other F-MuLV-infected SCID mice. Lane 1 (positive control), SCID mouse with known viral integration adjacent to the myb gene. Lanes 3, 8, 10, 12, 15 and 20, F-MuLV-infected SCID mice display bands of approximate size compared to the positive control. Negative controls are as follows: lanes 21 and 22, spleen DNA from non-infected SCID mice; lane 23 , spleen DNA from non-infected CB17 mouse; lane $24, \mathrm{H}_{2} \mathrm{O}$ (no template) control. 


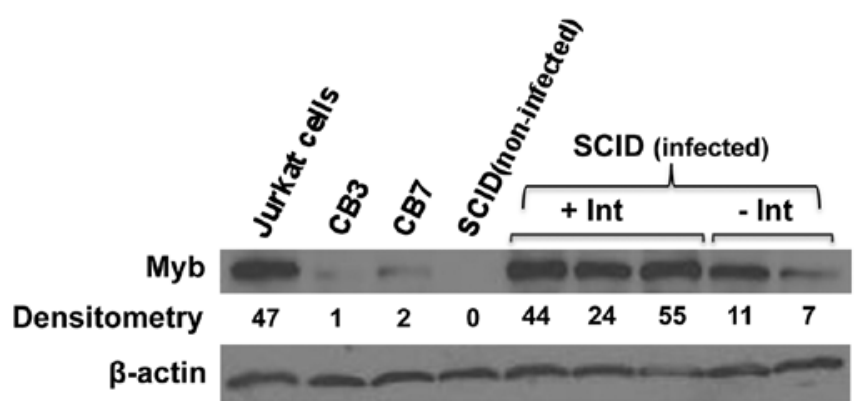

Figure 5. Expression of Myb in mice with F-MuLV-integration at the myb locus. Expression levels of the Myb protein in isolated splenocytes from F-MuLV-infected SCID mice with or without integration (Int) at the myb locus were analyzed by western blotting. Jurkat cells were used as a positive control. F-MuLV-induced erythroleukemic cell lines, CB3 and CB7, display integration at the $f i-1$ locus, causing Fli-1 overexpression. Presented values, which represent the density of each band, are normalized to the CB3 band. $\beta$-actin served as loading control.

similarly results in the upregulation of the Myb protein, we performed western blot analysis to detect the expression levels of Myb in spleen cells of F-MuLV-infected SCID mice. As shown in Fig. 5 leukemic SCID mice displayed elevated Myb expression irrespective of the myb rearrangement. However, samples with viral integration at the myb locus, compared to those negative for this integration, displayed higher Myb expression. The F-MuLV-induced erythroleukemic CB3 and CB7 cell lines, which harbour viral integration at the $f i-1$ locus, displayed weaker expression of Myb, when compared to spleen cells from leukemic SCID mice. Jurkat cells, which are known to express high levels of the Myb protein, were used as positive control.

F-MuLV-infected SCID mice with viral integration at the myb locus develop myeloid leukemia. It has been well documented that Myb overexpression is associated with the progression of myeloid leukemias. To characterize the hematopoietic phenotype of tumors induced by F-MuLV in SCID mice, spleen cells from these mice were cultured on methylcellulose (see Materials and methods) and after 7 days colonies were plucked, stained with May-Grunwald/Giemsa and observed under a microscope. Compared to spleen cells from non-infected mice, the majority of F-MuLV-infected SCID spleen cells revealed the morphology of mature and immature macrophages, monocytes and neutrophils (Fig. 6). Flow cytometry analysis of these cells demonstrated that they were 75 and $90 \%$, respectively, positive for myeloid markers CD11b and CD71 (Table II). These cells were nearly negative for expression of CD19, CD3, TER119 and Scal cell surface markers. These results indicate that F-MuLV-induced leukemia in SCID mice is of myeloid origin and are consistent with the well-known role of $m y b$ in the development of myelogenous leukemia (10).

\section{Discussion}

Integration of F-MuLV at the $f l i-1$ locus has been shown to be the pivotal genetic event for erythroleukemogenesis in mice (9). In the current study we have shown that F-MuLV infection of mice with the scid mutation results in the development of myeloid
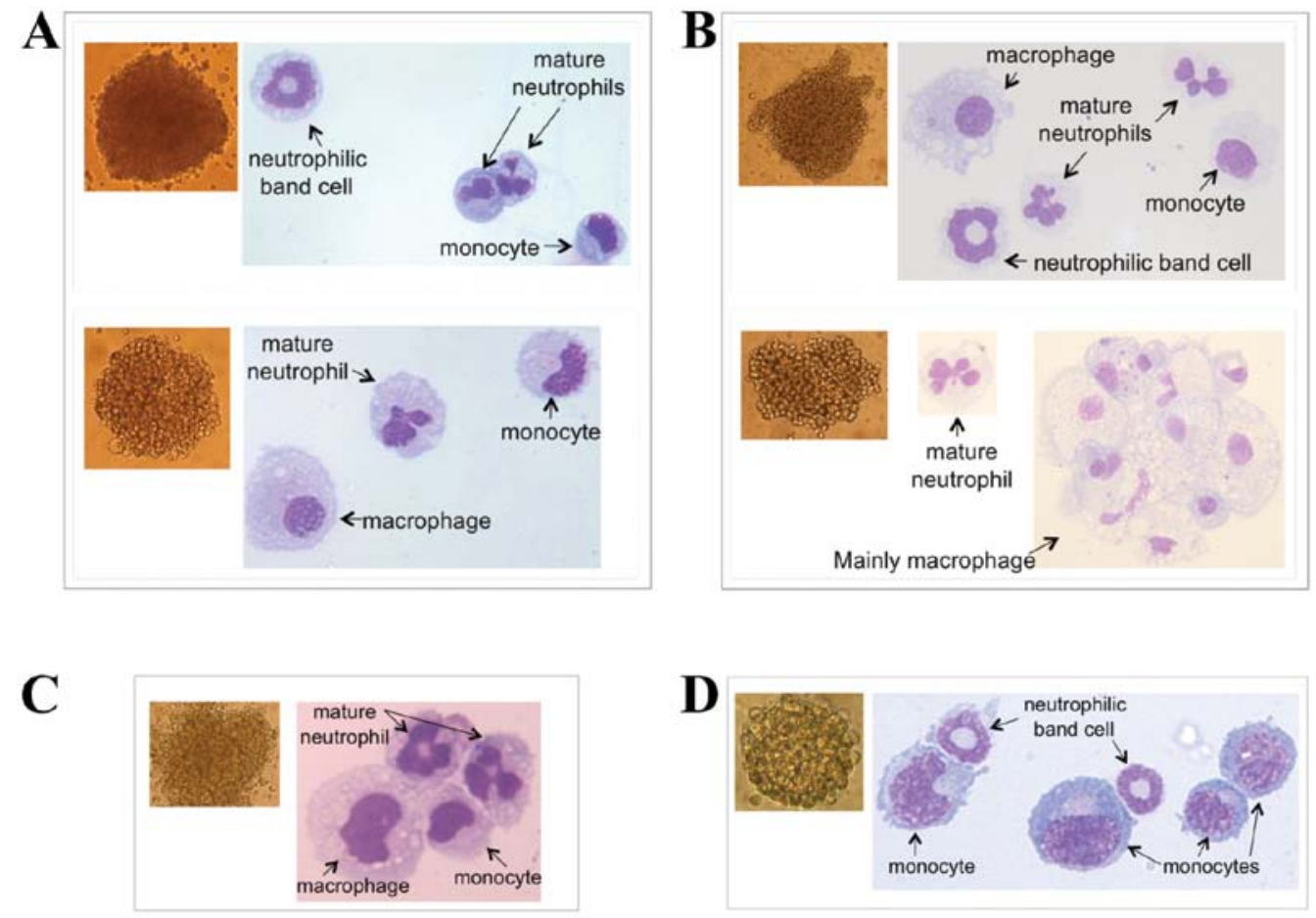

Figure 6. Colonies of myeloid origin in F-MuLV-infected SCID mice. Splenocytes from F-MuLV-infected SCID mice were cultured on methylcellulose and stained with Giemsa/May-Grunwald. Mature and immature macrophages, monocytes and neutrophils were observed, indicating myeloid lineage origin. (A and B) Cells are from 2 tumors displaying viral integration at $\sim 62 \mathrm{~kb}$ upstream of the $m y b$ locus. (C and D) Cells are from tumors without $m y b$ integration. Cells in panel D display viral integration within prdm16, rhoq, ahdcl, zc3h4 and $m s h 3$. 
Table II. Altered cell surface marker expression in F-MuLVinfected SCID mice.

\begin{tabular}{lc}
\hline Cell surface marker & \% of expression \pm SD \\
\hline CD19 & $0.2 \pm 0.1$ \\
CD3 & $0.2 \pm 0.1$ \\
B220 & $1.0 \pm 0.3$ \\
Gr-1 & $11.7 \pm 0.9$ \\
CD11b & $76.3 \pm 0.7$ \\
TER119 & 0 \\
CD71 & $91.0 \pm 0.6$ \\
cKit & $1 \pm 0$ \\
Sca1 & 0 \\
CD34 & $1.1 \pm 0.1$ \\
\hline
\end{tabular}

The spleen cell lines established from F-MuLV-infected SCID mice were analyzed by flow cytometry for the expression of the indicated cell surface markers. One million cells were stained with antibodies against CD19, CD3, B220, Gr-1, CD11b, TER119, CD71, cKit, Sca1 or CD34 surface markers. The results indicate the presence of myeloid progenitor cells lacking expression of CD19, CD3, TER119 and Sca1 markers. Data are representative of four independent experiments where values represent the mean $\pm \mathrm{SD}$.

leukemia, not erythroleukemia. This led us to the discovery of a novel F-MuLV integration site at the $m y b$ locus, which we termed fil-4. These results suggest that the scid mutation results in alteration of the common viral integration site resulting in transformation of the myeloid lineage.

The polycythemic strain of Friend virus (FV-P), a member of murine leukemia virus family, induces leukemia in susceptible strains of mice as a result of integration at the spleen focus forming virus integration-1 (spi-1/PU.I) locus (11). In SCID mice, however, in spite of the viral integration into the host genome none of the FV-P-inoculated mice exhibited viral insertion at the spi-1/PU.1 locus and they were resistant to the development of virus-induced leukemia (12). This is consistent with our study that mice with the scid mutation were resistant to F-MuLV-induced erythroleukemia and virus integration at the $f l i-1$ locus did not occur in these mice. SCID mice lack DNA-dependent protein kinase (DNA-PK), an enzyme that facilitates stable integration of retrovirus into the host genome (13). It is therefore possible that the resistance to leukemogenesis in the F-MuLV-infected mice (our study) and the FV-infected mice (12) is due to lower levels of overall random viral integration and consequently lower probability of specific integration at the $f i-1$ or Spi-1 loci. In agreement with these results and the hypothesis that DNA-PK is required for viral integration, Daniel et al showed that mouse SCID cells infected with retroviruses exhibited a substantial reduction in retroviral integration into host DNA as compared with control cells (14). Moreover, other studies have suggested that DNA repair deficient cells can lose integrated foreign DNA as they proliferate $(15,16)$.

In the current study we observed that although F-MuLV-inoculated SCID mice develop disease, as indicated by hepatosplenomegaly and emergence of leukemic blasts in the spleen, they do not exhibit F-MuLV integration at the $f l i-1$ locus. This suggests involvement of genes other than $f l i-1$ in induction of this malignancy. One of the viral integration sites that frequently identified in the SCID-derived tumors was about $62 \mathrm{~kb}$ upstream of the $m y b$ gene. This F-MuLV viral integration occurs in a region of the myb locus that has not been previously identified in any mouse retrovirus-induced leukemia. The high frequency of proviral integration in this site (35\%) suggests it may play an important role in the development of leukemia in SCID mice.

A previous study has demonstrated that F-MuLV integration at $90 \mathrm{~kb}$ upstream of $e v i 1$ activated $m y b$ expression (17) and also Moloney murine leukemia virus integration approximately 30 or $270 \mathrm{~kb}$ downstream of the $m y c$ gene activated Myc protein expression (18). We determined expression of Myb protein in spleen cells of the F-MuLV-infected mice with or without integration upstream of the myb. Both groups of mice (positive or negative for $m y b$ integration) displayed overexpression of Myb, but higher expression was detected in leukemias that acquired insertional activation of this locus. In agreement with our results, in many studies that showed viral integration at or close to the $m y b$ locus, expression of the Myb protein was detected in both groups of mice with or without integration of virus (18-21). It is therefore possible that direct or indirect activation of $m y b$ occurs in all these leukemias through various mechanisms. Our results therefore suggest that in SCID mice a shift in the site of proviral integration is likely the cause of switch in leukenogenesis from erythroleukemia to myelogenous leukemia.

In the current study, in addition to the $m y b$ gene, we identified 14 other proviral insertion sites, with 7 of them interrupting a gene (Table I). Some of the genes flanking viral insertion sites have been previously associated with leukemogenesis. For instance, $P R$ domain containing 16 ( $p r d m 16)$, one of the genes interrupted by F-MuLV, has been associated with myeloid leukemia. High expression of prdm16 has been reported in AML-associated translocations $\mathrm{t}(1 ; 3)(\mathrm{p} 36 ; \mathrm{q} 21)$ and $\mathrm{t}(1 ; 21)$ (p36;q15) as a consequence of its juxtaposition to the enhancer element of Ribophorin 1 at 3q21 $(22,23)$ or to its fusion with $A M L 1$ at 21q15 (24). The PRDM16 locus encodes two proteins: full length and short form (sPRDM16) (25). The short form, which initiates from a start codon within exon 4 of $\operatorname{prdm} 16$, has the potential to be oncogenic in humans and mice $(26,27)$. We determined F-MuLV insertion site at position 153,956,624 of chromosome 4 (Table I), which locates at intron 1 of prdm16 and could lead to overexpression of the oncogenic SPRDM16.

Another example of an identified F-MuLV integration site with potential association with leukemogenesis, is viral insertion at position 51,537,815 on chromosome 17 (Table I). The closest downstream gene to this insertion site is special AT-rich sequence binding protein 1 (SATB1), which is a long-range regulator of spi-1/PU.1 and its overexpression increased Spi-1/PU.1 expression (28). Spi-1/PU.1 is an Ets transcription factor with multiple roles during normal hematopoiesis (29). It is essential for myeloid development, and its disruption can lead to a differentiation block of hematopoietic stem cells to common myeloid or lymphoid progenitors (30). Even moderate decreases in Spi-1/PU.1 expression may contribute to development of myeloid leukemia and therefore its regulation is essential to prevent leukemogenesis (28). F-MuLV insertion adjacent to $S A T B 1$ has the potential outcome of downregulating this gene and development of malignancy. 
In summary, we showed that F-MuLV induces myeloid leukemia in SCID mice. We identified a total of 15 proviral integration sites in F-MuLV-infected SCID mice, with some of them (myb, prmd16 and SATB1) known for inducing myeloid leukemia. These results indicate that F-MuLV-inoculated SCID mice, compared to CB17 controls exhibit an altered pattern of viral integration that leads to development of myeloid leukemia.

\section{Acknowledgements}

We would like to thank Melanie Suttar for excellent secretarial assistant. This study was supported by a grant from the Canadian Institute of Health Research (CIHR) to Y.B.-D. (MOP-110952).

\section{References}

1. Neil JC and Cameron ER: Retroviral insertion sites and cancer: fountain of all knowledge? Cancer Cell 2: 253-255, 2002.

2. Tamir A, Howard J, Higgins RR, Li Y, Berger L, Zacksenhaus E, Reis $\mathrm{M}$ and Ben-David Y: Fli-1, an Ets-related transcription factor, regulates erythropoietin-induced erythroid proliferation and differentiation: evidence for direct transcriptional repression of the $\mathrm{Rb}$ gene during differentiation. Mol Cell Biol 19: 4452-4464, 1999 .

3. Ben-David Y, Prideaux VR, Chow V, Benchimol S and Bernstein A: Inactivation of the p53 oncogene by internal deletion or retroviral integration in erythroleukemic cell lines induced by Friend leukemia virus. Oncogene 3: 179-185, 1988.

4. Li YJ, Higgins RR, Pak BJ, Shivdasani RA, Ney PA, Archer M and Ben-David Y: p45(NFE2) is a negative regulator of erythroid proliferation which contributes to the progression of Friend virus-induced erythroleukemias. Mol Cell Biol 21: 73-80, 2001

5. Cui JW, Li YJ, Sarkar A, Brown J, Tan YH, Premyslova M, Michaud C, Iscove N, Wang GJ and Ben-David Y: Retroviral insertional activation of the $\mathrm{Fli}-3$ locus in erythroleukemias encoding a cluster of microRNAs that convert Epo-induced differentiation to proliferation. Blood 110: 2631-2640, 2007.

6. Shaked Y, Cervi D, Neuman M, Pak B, Kerbel RS and Ben-David Y: Splenic microenvironment is a source of angiogenesis/inflammatory mediators accelerating the extramedullary expansion of murine erythroleukemic cells. Blood 105: 4500-4507, 2005

7. Oliff AI, Hager GL, Chang GH, Scolnick EM, Chan HW and Lowy DR: Transfection of molecularly cloned Friend murine leukemia virus DNA yields a highly leukemogenic helperindependent type C virus. J Virol 33: 475-486, 1980.

8. Moreau-Gachelin F, Tavitian A and Tambourin P: Spi-1 is a putative oncongene in virally induced murine erythroleukemias. Nature 331: 277-280, 1988

9. Ben-David Y, Giddens EG, Letwin K and Bernstein A: Erythroleukemia induction by Friend murine leukemia virus: insertional activation of a new member of the ets gene family, Fli-1, closely linked to c-ets-1. Genes Dev 5: 908-918, 1991

10. Wolff L: Myb-induced transformation. Crit Rev Oncog 7: 245-260, 1996

11. Moreau-Gachelin F, Wendling F, Molina T, Denis N, Titeux M, Grimber G, Briand P, Vainchenker W and Tavitian A: Spi-1/PU.1 transgenic mice develop multistep erythroleukemias. Mol Cell Biol 16: 2453-2463, 1996.

12. Hasegawa M, Yamaguchi S, Aizawa S, Ikeda H, Tatsumi K, Noda Y, Hirokawa K and Kitagawa M: Resistance against Friend leukemia virus-induced leukemogenesis in DNA-dependent protein kinase (DNA-PK)-deficient scid mice associated with defective viral integration at the Spi-1 and Fli-1 site. Leukemia Res 29: 933-942, 2005.

13. Daniel R, Katz RA and Skalka AM: A role for DNA-PK in retroviral DNA integration. Science 284: 644-647, 1999.
14. Daniel R, Katz RA, Merkel G, Hittle JC, Yen TJ and Skalka AM: Wortmannin potentiates integrase-mediated killing of lymphocytes and reduces the efficiency of stable transduction by retroviruses. Mol Cell Biol 21: 1164-1172, 2001.

15. Wurtele H, Little KCE and Chartrand P: Illegitimate DNA integration in mammalian cells. Gene Ther 10: 1791-1799, 2003.

16. Mayne LV, Jones T, Dean SW, Harcourt SA, Lowe JE, Priestley A, Steingrimsdottir H, Sykes H, Green HL and Lehmann R: SV40-transformed normal and DNA-repair-deficient human fibroblasts can be transfected with high frequency but retain only limited amounts of integrated DNA. Gene 66: 65-76, 1988.

17. Bartholomew $\mathrm{C}$ and Ihle JN: Retroviral insertions 90 kilobases proximal to the Evi-1 myeloid transforming gene activate transcription from the normal promoter. Mol Cell Biol 11: 1820-1828, 1991.

18. Lazo PA, Lee JS and Tsichlis PN: Long-distance activation of the Myc protooncogene by provirus insertion in Mlvil or Mlvi4 in rat T-cell lymphomas. Proc Natl Acad Sci USA 87: 170-173, 1990.

19. Bedigian HG, Johnson DA, Jenkins NA, Copeland NG and Evans R: Spontaneous and induced leukemias of myeloid origin in recombinant inbred BXH mice. J Virol 51: 586-594, 1984.

20. Largaespada DL, Brannan CI, Jenkins NA and Copeland NG: Nf1 deficiency causes Ras-mediated granulocyte/macrophage stimulating factor hypersensitivity and chronic myeloid leukemia. Nat Genet 12: 137-143, 1996.

21. Blaydes SM, Kogan SC, Truong BH, Gilbert DJ, Jenkins NA Copeland NG, Largaespada DA and Brannan CI: Retroviral integration at the Epil locus cooperates with the $N f 1$ gene loss in the progression to acute myeloid leukemia. J Virol 75: 9427-9434, 2001.

22. Shimizu S, Suzukawa K, Kodera T, Nagasawa T, Abe T, Taniwaki M, Yagasaki F, Tanaka H, Fujisawa S, Johansson B, Ahlgren T, Yokota J and Morishita K: Identification of breakpoint cluster regions at $1 \mathrm{p} 36.3$ and $3 \mathrm{q} 21$ in hematologic malignancies with $\mathrm{t}(1 ; 3)(\mathrm{p} 36 ; \mathrm{q} 21)$. Genes Chromosomes Cancer 27: 229-238, 2000.

23. Mochizuki N, Shimizu S, Nagasawa T, Tanaka H, Taniwaki M, Yokota J and Morishita K: A novel gene, MEL1, mapped to 1p36.3 is highly homologous to the MDS1/EVI1 gene and is transcriptionally activated in $\mathrm{t}(1 ; 3)(\mathrm{p} 36 ; \mathrm{q} 21)$-positive leukemia cells. Blood 96: 3209-3214, 2000.

24. Sakai I, Tamura T, Narumi H, Uchida N, Yakushijin Y, Hato T, Fujita S and Yasukawa M: Novel RUNX1-PRDM16 fusion transcripts in a patient with acute myeloid leukemia showing $\mathrm{t}(1 ; 21)$ (p36;q22). Genes Chromosomes Cancer 44: 265-270, 2005.

25. Nishikata I, Sasaki H, Iga M, Tateno Y, Imayoshi S, Asou N, Nakamura T and Morishita K: A novel EVI1 gene family, MEL1, lacking a PR domain (MEL1S) is expressed mainly in $\mathrm{t}(1 ; 3)(\mathrm{p} 36 ; \mathrm{q} 21)$-positive AML and blocks G-CSF-induced myeloid differentiation. Blood 102: 3323-3332, 2003.

26. Xiao Z, Zhang M, Liu X, Zhang Y, Yang L and Hao Y: MEL1S, not MEL1, is overexpressed in myelodysplastic syndrome patients with $\mathrm{t}(1 ; 3)(\mathrm{p} 36 ; \mathrm{q} 21)$. Leuk Res 30: 332-334, 2006

27. Du Y, Jenkins NA and Copeland NG: Insertional mutagenesis identifies genes that promote the immortalization of primary bone marrow progenitor cells. Blood 106: 3932-3939, 2005

28. Steidl U, Steidl C, Ebralidze A, Chapuy B, Han HJ, Will B, Rosenbauer F, Becker A, Wagner K, Koschmieder S, Kobayashi S, Costa DB, Schulz T, O'Brien KB, Verhaak RGW, Griesinger F and Tenen DG: A distal single nucleotide polymorphism alters long-range regulation of the PU.1 gene in acute myeloid leukemia. J Clin Invest 117: 2611-2620, 2007.

29. Tenen DG: Disruption of differentiation in human cancer: AML shows the way. Nat Rev Cancer 3: 89-101, 2003.

30. Iwasaki H, Somoza C, Shigematsu H, Duprez EA, Iwasaki-Arai J, Mizuno S, Arinobu Y, Geary K, Zhang P, Dayaram T, Fenyus ML, Elf S, Chan S, Kastner P, Huettner CS, Murray R, Tenen DG and Akashi K: Distinctive and indispensable roles of PU.1 in maintenance of hematopoietic stem cells and their differentiation. Blood 106: 1590-1600, 2005. 